structor, is readly to meet the diffeulties, but he was not wiliting to avoid them at once by having a more simple scheme to work out. It is so much the more to be wondered at, if this clever aëronaut has not adopted this policy, inasmuch as he does not profess to go against the wind, but to design a contrivance which may help aëronauts in using the wind for a certain purpose, as returning to Paris from a town located at some distance, as Lille, Le Mans, \&c. M. Dupuy de Lome intends to attain the desired result by making a definite angle with the direction of the reigning wind, which supposes on the part of the aerronant some previous knowledge of the state of atmospheric currents, their change of duration, and different directions at different elevations; the principal feature of his intended directing balloon being the grand idea of having the motive power like an auxiliary implement for giving to the balloon differential motions. It does not, of course, prevent the aeronaut from using the deflections and variations of the wind according to the elevation of his balloon at any moment. The working out of these aèrial manouvies supposes necessarily that aërial navigators can know at any moment the place where they are. It requires constant attention from the aerrial travellers, who are supposed to be supplied with every possible instrument for looking over the land and finding the places on the map prepared for that very purpose. It would be of itself a most interesting chapter, the better construction of such maps, as well as the determination of the means by which public anthoritics could give warnings to the aërial travellers. But in the present state of things, I should not be justified if I dicl not abstain from giving details which may prove useful to the invaders of my native land. I will be satisfied with saying, moreover, that the taking of the point in sailors' fashion is quite out of the question. The only condition is the view of the land remaining always at the command of the observer, or only being lost for short intervals, during which more than the usual attention is required. I have invented an apparatus called an aërial planchette, for helping aerronauts in the determination of their way, but from the experience of my last excursion I have lost every confidence in niy instrument. I think that it is quite useless; the only thing required being good maps and better eyes, helped by powerful opera-glasses. The power of these can be enlarged by a very simple contrivance, which I mention merely to show that I know what is still to be done in this respect.

The question of the motive power to be employed is not of so much importance as was supposed at the frist instance; and it is very easy to understand why, admitting that we want only a slow motion. I should not object, of course, to a quick displacenent; but $I$ am satisfied it cannot be obtained except by contrivances very difficult to imagine, and even more to realise, and besides it is not required for the special purpose in view, the returning to Paris from a French city which German armies have not occupied. The rate of motion will be improved by degrees, and will not amount to a large increase, except by the use of steam engines, whicli requires a great many preliminary steps to prevent the gas of the balloon from being lighted by the fire from the furnace, which would lead to the destruction of the balloon and of the aëronauts. The simplest contrivance will be the best if it proves useful. I should advise to arrange the notor apparatus so that it could be used by hand, and, besides, that it could be very easily thrown overboard like ballast in case of need. These two conditions being of much importance for our purpose, if I start for Paris, which I hope will be the case, I shall adhere strictly to them.

I have no objection to use a rudder, which may be constructed in a mamner very easy to understand, but I should feel very much disposed to dispense with it. I think that a propelling machine may be arrangerl so that no rudder at all will be put into operation. I am afraid to give more substantial explanations, which could hardly be offered without giving a full knowledge of my intended construction, which is not my purpose.

T'he contributions of M. Dupuy de Lome to the Comptes rendius, have been sharply commented upon by the Aeronaut, a special paper devoted to the aërial navigation worked out by the plus lowr't que l'air system, as inaugurated by Lalandelle and Nadas, and many other gentlemen of very little or no scientific qualifications. But every scientific man must confess that these interesting papers constitute by themselves a very valuable acquisition to reireral knowledge, independently of their special ain. M. Dupuy de Lome has given at the same time many calculations to show to what elevation a given balloon can attain under the conditions he has adopted, viz., constant fulness, and a certain excess of internal pressure for giving it a stability of form and of equilibrium.

Without quoting M. Dupuy de Lome's paper, and even cor. recting some parts of it, 1 will give a rough iden of the analytical questions involved in the calculation of the circumstances of an aerrostatical ascent. I suppose, firstly, that the air has no horizontal movement at all, and that the only questions are to ascertain the elevation which the balloon may reach, the time that may be required, and the velocity with which the balloon ascends at the various points of its vertical course, as well upwards as downwards. There are hesides two accessory suppositions which are required. The first is, that the balloon does not lose its gas by any exosmose during the experiment; and the second is that the temperature of the air, as well as the degree of moisture, is not altered in any degree. These conditions are hardly to be expected, but they are required for mathematically working out the analytical equations.

M. Dupuy de Lome, however, would not have been placed in a position to proceed with his calculations, if he had not very cleverly evaded the consideration of the other conditions, which are insuperable, owing to nur imperfect knowledge of the atmosphere, as we shall see hereafter.

W. DE FONVIELIE

\section{PROF. WILLIAMSON'S INAUGURAL LECTURE TO THE FACULTY OF SCIENCE AT UNIVERSITY COLLEGE, LONDON}

THE great value of scientific knowledge as a means of culture, a promoter of civilisation, and one of the most powerful levers of national prosperity, seems at least to receive its due acknowledgment in the land of Bacon and New'ton, Sir Humphry Davy and Faraday. The recent efforts to introduce science into the public schools of England appear as a consequence of this recognition. A great variety of opinion, however, exists as regards the mode by which scientific knowledge ought to be imparted to the people. Some believe that a young farmer ought to be taught agricultural chemistry, the man at the furnace the chemistry of iron melting, and the maker of colours the chemistry of colours. "This is what is called by many "technical education," for the promotion of which great efforts have been made of late. Technical education in this sense would be a mistake. It would not be difficult to show that it is impossible to teach, with any considerable effect, agricultural chemistry, which is the application of certain chemical principles to Agriculture, without a knowledge of these principles. These, with others, form part of the science of Chemistry, and it is clearly absurd to isolate them and teach their application in some par. ticular case. The working classes of England want a knowledge of the elements of pure science; and they are sure to make useful application of this knowledge as soon as an opportunity offers itself. In this sense Professor Williamson expresses himself in his admirable lecture, "A Plea for Pure Science," * which on account of its sound views on some of the most important questions of the day, we recommend to the attention of our readers. On p. 3 Prof. Williamson says, "Now there are in edx: cation two great national parties, corresponding to the two most different points of view from which the preparation of any young person for his career in life can be considered. I submit that the progress of education will be proportional to the consistency and completeness with which the functions of these two parties are systematised and developed.

"The first step towards that object is to know and acknowledise their respective characteristics.

"One party looks to the special duties for which a young person has to be prepared and the material difficulties which he is ex. pected to encounter. They see that the success and happiness of each individual are propertional to the efficiency with which he discharges the aggregate of the special duties of his station in life; and they accoidingly recommend that each youth be placed in circumstances which may induce him to imitate accurately the doings of some one who is known to be successful in a station. such as he is intended to occupy. The other party looks to the general qualifications which experience has shown to be most important for any success in life; and to the means by which they are most effectually acquired. They see that men who have been taught to understand and apply the best-known general principles are able to master a given set of practical details with a facility and completeness which other men do not attain. They know that a general principle of nature is an instrument of " "A Plca for Pure Science." By A. W. Williamson, Ph.D., F.R.S. 
thought applicable to the explanation of an infinite variety of phenomena, and they recommend that every one be placed in his youth somewhere where he may best learn such general principles. The first party takes little account of the develojment of the mental powers as a distinct object to be aimed at in education; the second attends but little to special operations.

"The former recommends special or technical instruction with a direct view to material success in a particular business, the direct aim of the latter is to educate and strengthen each individual mind. The essential differences between them arise from the fact that they look at the question from opposite sides, and respectively put forward what they see most clearly."

After this sketch of the outline of the characteristics of the two great parties, Professor Williamson describes some results of the arran rements recommended by them respectively. The great aim and object of science is to systematise our knowledge ; and the discovery of an idea which helps to arrange any considerable number of facts in such a manner as to facilitate their apprehension, is the highest result of scientific work. We are then led in an admirable manner from the periodical disappearance of the sun to the law of gravitation as a model of scientific work. But it must not be supposed that the application of science to practical purposes is the greatest reward of scientific work. We read on page $12-$

"To any one possessing a clear and vigorous mind, the acquisition of an idea which helps to explain things is a source of intense pleasure. He feels that it enlarges the scope of his mind, and gives him new power; and when facts, previously unintelligible, are explained by the aid of such an idea, they immediately acquire vivid interest and special value to his mind; such facts seem to gain life by acquiring an intelligible place in the system of nature.

"I believe that the triumphant feeling of the enlargement of his faculties which is experienced by a real student in the acquisition of any new law or principle of nature, is the most direct and vivid reward of his labours. The best and truest, as weil as the most rapid progress in study, is made for the sake of that reward. Whoever has once enjoyed it will gladly seize any opportunities of wrestling, as far as his powers permit, with new difficulties, and mastering new ideas.

"It has been said that the hapiness of an individual results from the dive excrcise of his various facult es, and this is surely not le.st true of the highest faculties of the mind; certainly those who have the power of understanding the wonders of nature derive great hav iness frum leaming to employ it. It is like the pleasure which a m.tn of herithy anil vigorous frame experiences $i$ climbing a mountain peak, and in enjoying, in proportion as he rises, a wider and more commanding view of things below."

Our space does not permit us to follow the author into the study of the conditions under which science flourishes, and does most effectively the good which it has to do, and we must content ourselves with a quotation of his description of the usual results which follow a system of special professional pupilage:

"But it often happens (page 15 ) that a man learns ihoroughly the particulars of a business, as practised in some one successful case, and although he has sufficient capital and industrious habits, fails to realise similar results elsewhere.

"For instance, he has learnt and practised the management of a particular farm, and then takes a lease of one in another district. He purchases implements exactly similar to those which he has been using, and gets sheep and cattle of the same breeds. He adspts the same rotation of crops, and spares no pains to make everything go on precisely in the same way as that to which he has been accustomed.

" $H$ is first year is unprofitable ; but he looks forward hopefully to better results, when things will have got into better working order. But the second and third year only bring more losses, and he is ultimately compelled to give up the farm.

"The next tenant is perhaps a man who has learnt the management of an adjoining farm, wh chl happen to be in size, in soil, \&c., very much like it. He uses ploughs and other implements which have been found to suit the soil, and gets breets of sheep and cattle which thrive in that $p$ ut of the country. He adopts the same rotation of crops and system of manuring which is customary in that district, and carefully imitates what he hat seen to succeed, under conditions similar to his own. The result $s$, hat he goes on steadily year after year making a fair profit.

"Both of these men were mere servile imitators of what they had seen, and both had been taught to believe that a practical man ought to be nothing more, and that all theories are dangerous. Yet one failed while the other succeeded. We ought not to be surprised at the failure of the one, so much as at the success of the other, which was due to the exceptional circumstance of his finding a farm which admitted of being profitably managed upon exactly the same system."

Men of business, in the opinion of our author, ought to have not only a knowledge of things, but also of principles; and they must be able to use their knowledge of these things and principles for the purpose of bringing ahout special results in fact they must have a knowledge of the laws of nature, and skill in the methuds of applying that knowledge to experimental purposes. Their power of bringing about the material results from which they derive profit is proportional to the amount of such knowledge and skill which they possess.

And here we must break off our account of an essay which, no doubt, wrill greatly help to clear up our ideas about scientific and technical education.

\section{ZOOLOGY}

\section{Researches on the Amøba}

THE minute masses of protoplasm termed Amobæ have been recently examined by $M$. V. Czerny, in relation to their resistance to reagents, and bis results have been published in Schultze's "Archiv für Mikroscopische Anatomie," p. I58. He finds that the power of resistance to the action of solutions of common salt varies considerably in different individuals. In solutions containing one part to four hundred of water none died, but in those containing one to three hundred many died; whilst others, especially the quiescent ones, still lived in solutions containing one per cent., or more. None, however, survived when suddenly placed in a two per cent. solution. It is interesting to observe, however, that these lowly organised beings possess a certain adaptability to external conditions--a power of acclimatisation as it were, enabling them, if these conditions undergo slow alterations, to accommodate themselves to their new and modified surroundings. Thus, if the strength of the solution were gradually raised, it was found that some Amœbæ could continue to exist in solutions of four per cent. of salt. M. Czerny corroborates the statements already made by Kiilne, that, on exposure to weak saline solutions, Amoebre thrust forth numerous extremely delicate processes resimbling cilia, and that they undergo fission. It is worthy of remark that the partially double contour of the Antéta bilabiata, which has led to the admission of a double contoured membrane in this species, is resolved, when examined with a No. Io Hartnack immersion lens, into a number of closely aggregated, extremely minute toothlets, which, like the stinging cells, cover the whole surface of the body.

M. Engelmann has made some observations on the electrical excitation of the Amoba of the Arcella in the fifth volume of the "Nederlandische Archiv voor geneesen Natuur kunde," p. 28. His investigations were conducted in a moist gas chamber, with unpolarisable electrodes, the stimulus consisting of a single opening induction shock. In Amaba diffuens, as Kühne had showed previously, the results of the excitation differ according to whether the individual is in the active or in the quiescent condition. In the former condition, that is, when the animal is elongated or club-shaped and homogeneous, and its protoplasm seems to be flowing continuously in one direction, a very slight stimulus retards or altogether arrests the current, though it speedily recommences, the period of arrest not exceeding at most five seconds. If, however, the stimulus has been a little stronger, in addition to the arrest of the protoplasmic movements, a condensation and shortening of the whole animal occurs, and at a subsequent period perfectly transparent projections form in the anterior part of the body, into which the highly granular protoplasm streams until the original form of the Amoba, which sometimes moves forward with great rapidity, is re-established. The length of time occupied in these changes may amount with tolerably strong currents to ab ut from one to two minutes. If the excitation be applied to the quiescent animal, the protoplasmic movements first cease, the mass assumes the spherical form, but instead of remaining quiescent, it now begins to move from place to place, in which a tive condition it may remain for a long time. From these ex. F.eriments, and from others performed upon specimens of Arcella, containin air-vesicles M. Engelmann draws the conclusion that protoplasm, in consequence of electrical excitation, transitorily assumes the mechanical properties of a fluid. 